\title{
O corpo na psicanálise freudiana: suas relações com a consciência e o inconsciente
}

\section{The Body in Freudian Psychoanalysis: Its Relations to the Conscious and Unconscious}

\author{
Ana Carolina Soliva Soria \\ Docente do Departamento de Filosofia e Metodologia das Ciências, Universidade Federal de São Carlos \\ - UFSCar, São Carlos, SP, Brasil.
}

Resumo: O presente artigo visa investigar a relação paradoxal que o corpo mantém com a alma na teoria freudiana. Por um lado, ele é a fonte de pulsões que têm por fim alcançar o prazer, desconsiderando o exame de realidade; por outro, ele é o ponto fundamental para a construção do julgamento de realidade.

Palavras-chave: Freud; corpo; consciência; Inconsciente; pulsão

Abstract: This article aims at examining a paradoxical relationship that the body maintains with the soul in Freudian theory. On the one hand, it is the source of the drives that have the end of pleasure, disregarding the examination of reality; on the other hand, it is the fundamental point for a construction of the judgment of reality.

Keywords: Freud; body; consciousness; unconscious; drive 
Quando pensamos no lugar do corpo na teoria psicanalítica, sobretudo nos textos psicanalíticos iniciais, podemos, num primeiro momento, pensar que ele é descartado por Freud como algo separado do psiquismo. O próprio texto da Interpretação dos sonhos (1900) parece nos dar elementos para pensarmos isso. Lemos ali:

\begin{abstract}
Vamos deixar de lado o fato de que o aparelho anímico de que se trata aqui nos é conhecido também como preparado anatômico, e vamos tomar o cuidado de não cair em tentação de determinar a localidade (Lokalität) psíquica como algo anatômico. Ficamos no solo psicológico e pensamos somente seguir a exigência de representar (vorstellen) o instrumento de que se servem os trabalhos anímicos como um microscópio composto, um aparelho fotográfico ou algo semelhante. A localidade (Lokalität) psíquica corresponde então a um lugar (Orte) no interior do aparelho, no qual se efetivam os primeiros níveis da imagem. (FREUD, 1900 [1899], p. 541)
\end{abstract}

Tomando isoladamente esse trecho, poderíamos pensar que o corpo é abandonado nos textos freudianos, e que aquilo que interessa ao autor é apenas o que está no campo representacional. Ou ainda, que a psicanálise deve se distanciar da investigação do preparado anatômico e que este é pressuposto apenas como base da representação, da qual nada se pode dizer a respeito. Estaríamos às voltas com uma espécie de "dualismo epistemológico" entre corpo e alma, em que a investigação desta estaria separada da daquele e subsistiria por si própria? A resposta a esse problema é, sem dúvida, negativa. Desde muito antes da publicação de 1900, Freud tem uma clara concepção de que corpo e alma estão em ação recíproca (Wechselwirkung), e que não se pode conhecer a segunda sem levar em conta sua relação com o primeiro. Exemplo claro de como a alma pode agir sobre o corpo encontramos nos fenômenos histéricos, que tanto intrigaram o autor no início da psicanálise.

Se corpo e alma determinam-se mutuamente, resta nos questionarmos como isso se dá. Ou, dito de outro modo, investigar quais as consequências que essa mútua determinação implica para a teoria freudiana. Para analisarmos esse problema, devemos levar em conta que a psicanálise é uma disciplina que investiga a relação entre instâncias psíquicas contrárias, a saber: a consciência (e ligada a ela, o pré-consciente) e o inconsciente. No texto $O$ inconsciente, de 1915, vemos claramente essa oposição. Freud define ali o inconsciente por qualidades contrárias as da consciência; sendo assim, tudo o que a consciência é, o inconsciente não é. A consciência está no tempo, guia-se pelas relações lógico-causais, não admite contradição entre ideias que se ligam em uma mesma cadeia de pensamento, norteia-se pelo princípio de realidade, etc. Já o inconsciente é o oposto disso: seus processos estão fora do tempo, admite ideias contraditórias em uma sequência de pensamento, o princípio é regido pelo princípio de prazer $^{1}$. Ora, essa característica de contrariedade entre as instâncias está também presente no modo como o psiquismo e o corpo se relacionam. Na psicanálise freudiana, vemos que paradoxalmente o corpo é a fonte dos impulsos que visam apenas o prazer e, por outro lado, é peça fundamental para que a consciência julgue a realidade das representações. Para entendermos melhor como esse problema é exposto nos textos de Freud, é necessário antes compreender o que o autor entende por inconsciente e como esta instância se relaciona com a consciência.

\title{
1. A gênese do conceito de inconsciente
}

Se compararmos os textos publicados por Freud em seu período dito "pré-psicanalítico" com o "psicanalítico", veremos que algo de fundamental importância acontece em 1897. Até essa data, a tópica psíquica era entendida de uma maneira bem diversa do

${ }^{1}$ A esse respeito, consultar o capítulo V de O inconsciente (1915a). Ver também: SORIA, 2012, p. 36. 
que virá a ser posteriormente. Em Estudos sobre histeria (1895), por exemplo, Freud afirma que a patologia se deve a um estado de dupla consciência: uma normal, que vive no instante presente e que permite o convívio com outras pessoas, e outra alienada, presa a certos eventos do passado, que recoloca experiências para o enfermo que apenas ele pode vivenciar. $\mathrm{O}$ tratamento da patologia, tal como exposto nessa época, consistia em colocar o histérico em um estado diferenciado de atenção, de tal modo que ele pudesse acessar ao conteúdo da memória pertencente à consciência alienada e expressá-lo em palavras. Essa rememoração dos conteúdos alienados deve ser acompanhada da descarga afetiva adequada ao evento, que o paciente não pôde expressar no momento em que o fato desagradável ocorreu (tais como choro, gritos, xigamentos etc.). A esse procedimento, deu-se o nome de método catártico.

Nessa obra, afirma-se que o conteúdo alienado é trazido à luz em uma ordem temporal inversa à de sua formação: primeiramente, chega-se aos mais recentes para, pouco a pouco, e com bastante dificuldade, alcançar os eventos traumáticos mais remotos. Já nessa época, Freud havia percebido que há no psiquismo uma força que resiste a aproximar-se dos conteúdos das recordações desagradáveis. Contudo, essas recordações ainda eram pensadas como efetivas (wirklich) (ou seja, como realmente tendo acontecido). Prova disso é claramente dada no relato do primeiro caso do livro, qual seja: Anna O. Quando tomada pelos processos de sua consciência alienada, a paciente revivia os fatos do ano anterior, cuja veracidade foi atestada por um diário que sua mãe manteve na época. Estas anotações permitiram constatar o valor inegavelmente objetivo do relato da enferma. Na investigação desse caso, vemos como, por exemplo, a paciente deixou de tomar água após assistir o cachorro de sua dama de companhia bebendo água de um copo. Ou como seu braço ficou paralisado após ter a impressão de ver, num estado de quase adormecimento, uma serpente sobre o seu pai, que estava doente e sob os seus cuidados. E mesmo que Freud afirme que há na base do trauma algo de sexual, essa sexualidade refere-se a fatos da vida adulta do indivíduo.

Nos Estudos sobre histeria, o passado a que se chega durante o tratamento se refere ainda a eventos recentes da vida do enfermo. Em textos posteriores, como Novas observações sobre as neuropsicoses de defesa (1896), Freud consegue tomar dos enfermos relatos de eventos traumáticos muito anteriores à vida adulta: chega-se ali aos anos iniciais da vida do paciente. E ao combinar a natureza sexual desses eventos com o valor objetivo do relato, o autor acaba por construir uma teoria que coloca como causa das enfermidades psíquicas abusos sexuais de crianças, em geral, por familiares próximos: o pai, um tio, um primo mais velho aparecem nos textos desse período como provocadores efetivos de uma sexualidade artificial, imposta em uma época imprópria: na infância. Lemos no texto de 1896: "Esses traumas sexuais têm de pertencer à tenra infância (à vivência antes da puberdade) e seu conteúdo tem de consistir numa irritação efetiva dos genitais (wirklicher Irritation der Genitalien) (por processos parecidos com o coito)" (FREUD, 1896, p. 380).

Pouco tempo depois, Freud não pode deixar de se questionar sobre os fundamentos de sua teoria. Enumera ele em uma carta ao seu amigo Fliess, datada de Viena, 21 de setembro de 1897, os motivos que o levaram a rever as ideias que até então embasaram sua teoria:

As contínuas desilusões nas tentativas de levar minha análise a sua consumação efetiva, a deserção da gente cuja enfermidade, durante algum tempo, pensei ter dominado, a demora do êxito completo com que eu havia contado e a possibilidade de explicar os êxitos parciais de outras maneiras, segundo a maneira habitual: eis aí o primeiro grupo \{de motivos\}. Depois, veio a surpresa diante do fato de que, em todos os casos, o pai tinha de ser apontado como pervertido, sem excluir o meu, a compreensão da inesperada frequência da histeria, na qual deveria se observar idêntica condição em todos os casos, embora, seja muito pouco provável que a perversão contra crianças seja difundida a esse ponto. (A perversão teria 
de ser incomensuravelmente mais frequente do que a histeria, pois a doença só aparece quando há uma acumulação de eventos e se adiciona a isso um fator que enfraquece a defesa). Em terceiro lugar, a certa intelecção de que no inconsciente, não há um signo da realidade, de modo que não se pode distinguir entre verdade e ficção que é investida com o afeto. (Assim, resta uma solução: a fantasia sexual se apropria quase sempre do tema dos pais). Em quarto lugar, a reflexão de que nas psicoses mais profundas, a recordação inconsciente não vem à tona, de modo que o segredo das vivências infantis não transparece nem mesmo no delírio \{Delirium\} mais confuso. E vendo assim que o inconsciente nunca supera a resistência do consciente, submerge também a expectativa de que na cura se poderia ir no sentido inverso, até a completo domesticação do inconsciente pelo consciente. (FREUD, 1950 [1897], p. 301-02)

Freud enumera aí quatro motivos que o levaram a abandonar a sua teoria das neuroses: primeiramente, por conta de uma dificuldade teórico-clínica de levar a cabo sua análise e a de seus pacientes e de encontrar uma explicação universalmente válida para a etiologia das neuroses; em segundo lugar, devido a um problema estatístico: nem todas as crianças que sofrem abusos semelhantes na infância acabam por desenvolver uma enfermidade psíquica, de tal modo que ter-se-ia de pressupor a existência de muito mais adultos perversos do que de enfermos, o que parece ser bastante improvável; em seguida, que a recordação dos fatos traumáticos dos enfermos, que parecia apontar para algo verdadeiro e de valor objetivo, pode não passar de uma fantasia, já que o no inconsciente não há julgamento algum de realidade; e finalmente, que através da clínica da psicose, dá-se conta de que o inconsciente pode jamais superar totalmente as resistências impostas aos seus conteúdos pela consciência, de tal modo que pode jamais deixar transparecer os seus segredos.

A partir desse momento, o relato de uma lembrança relacionada à enfermidade passará a ser visto como uma composição de traços do passado e do presente do indivíduo. Mas nem por isso terá um valor menos real: uma vez que no inconsciente não existe signo de realidade, não se pode diferenciar, do ponto de vista desta instância, fato imaginado de efetivo (wirklich). Aliás, como irá expor em textos posteriores, o signo de realidade é um atributo da consciência. $\mathrm{O}$ inconsciente, anterior a esta, não leva em conta tal signo; e mais ainda, ele o desconhece completamente. O inconsciente psicanalítico não é como a consciência alienada dos Estudos sobre histeria: ele não pode se esgotar no tornar-se consciente. Ao contrário, ele é uma "uma caldeira plena de excitações borbulhantes" (FREUD, 1933 [1932], p. 80), que desconhece a existência das formas que moldam as representações conscientes e as regras lógicas que as conectam. Ele é uma instância que quer cegamente, sem consciência de si ou da meta que seus impulsos devem alcançar. Sua fonte está no corpo, de onde brotam as pulsões. E uma vez que o corpo pode surgir, ao mesmo tempo, desejos diferentes e até mesmo contraditórios, no inconsciente não vigora a lei de não contradição. Vejamos esse problema mais de perto.

\section{O inconsciente, a consciência e o problema do julgamento de realidade}

A compreensão da sexualidade em Freud é de fundamental importância para a intelecção do que vem a ser o inconsciente e de como este se relaciona com o corpo. No conjunto de revisões que o psicanalista fez à sua teoria a partir de 1897 está também a reconfiguração daquele conceito. A ideia de uma sexualidade latente na infância, que se manifesta apenas na puberdade, já pronta, voltada para a relação heterossexual (com o privilégio dos órgãos genitais e visando a reprodução), e que relegue tudo o mais à perversão, é desconstruída por Freud em um texto de 1905, intitulado Três ensaios de teoria sexual. O primeiro dos três ensaios é dedicado à desmontagem dessa concepção. No segundo ensaio, assistimos à sua reconstrução: 
no início da vida do indivíduo, a sexualidade aparece apoiada na função biológica da sucção do leite (isto é, da auto-conservação), e pouco a pouco se torna independente desta. Ela passa então a se constituir, já na mais tenra infância, paralelamente aos impulsos de conservação de si, como um desvio destes. Isso porque a sexualidade opera em um nível distinto e paralelo àqueles. Freud irá propor que os impulsos sexuais, inicialmente não direcionada para a satisfação de uma parte específica do corpo (os genitais, por exemplo), brotam em qualquer uma das partes deste, em especial no que denomina zonas erógenas (isto é, pontos de maior sensibilidade sexual, tais como a boca, o ânus e os mamilos). Ela aparece como uma espécie de "comichão" em uma área específica do corpo, que leva o indivíduo a manipular essa parte até chegar ao término dessa sensação. O psiquismo não passa ao largo desse processo: a excitação gerada pela parte do corpo exerce uma pressão sobre ele que permite a formação de uma representação (a do "comichão") que tem como resposta uma ação motora, no sentido de manipular o próprio corpo na tentativa de aliviar o estímulo naquela parte.

Exemplo de como acontece o apoio da função sexual sobre a de auto-conservação pode ser encontrado na seguinte situação: uma criança que mama satisfaz sua fome e cumpre os desígnios da pulsão de auto-conservação. Para se alimentar, ela realiza um ato: o sugar. É sobre esse ato que se apoia a pulsão sexual. Contudo, sua satisfação não se dá com a ingestão do leite (objeto da pulsão de conservação de si). Sendo sua boca uma zona erógena e o modelo de sua satisfação tomado daquela pulsão, a satisfação das excitações sexuais que brotam na borá se dá pela repetição do ato de sugar. Mas não um objeto específico (como no ciclo auto-conservativo, em que se busca o seio para se ter o leite); ao contrário, procura-se qualquer objeto que se preste a ser sugado (o seio, mas também o próprio dedo, os lábios, um brinquedo, etc.).

Tanto as pulsões de auto-conservação quanto as sexuais têm como fonte o corpo. Contudo, o modo como elas atuam faz com que as pulsões de auto-conservação se prendam a objetos mais fixos de satisfação (para a fome, serve apenas o objeto que alimenta), enquanto que a pulsão sexual pode se satisfazer com qualquer objeto que sirva para extinguir a excitação na parte do corpo que lhe deu origem (inclusive o próprio corpo do indivíduo, segundo o modelo da satisfação auto-erótica). Escreve Freud no texto de 1905:

No sugar ou no mamar deleitoso podemos já observar as três características essenciais de uma exteriorização sexual infantil. Esta nasce apoiando-se em uma das funções corporais importantes para a vida, não conhece ainda nenhum objeto sexual, é auto-erótica, e sua meta sexual está sob o domínio de uma zona erógena. Antecipamos que estas características valem também para a maioria das outras manifestações da pulsão sexual infantil. (FREUD, 1905, p. 83)

Ora, e o que o modelo de satisfação auto-erótica significa? Significa que, se, por um lado, as pulsões de auto-conservação têm de levar em conta um objeto externo e rapidamente criar a representação psíquica de que para a sua satisfação de sua necessidade uma ação no mundo deve ser realizada, por outro, as pulsões sexuais podem prescindir dessa ação no mundo e encontrar satisfação no movimento de voltar-se sobre si mesmo, sobre seu próprio corpo. Isto quer dizer que as pulsões sexuais podem encontrar prazer sem ter de levar em conta se uma modificação no mundo foi ou não realizada. Contrariamente, as de auto-conservação devem permitir que o psiquismo crie mecanismos para que o indivíduo consiga, por meio de uma ação motora voluntária, encontrar os objetos corretos que a satisfaçam.

Temos com isso que as pulsões sexuais se guiarão apenas pelo que Freud denomina princípio de prazer, isto é, pelo evitar ao máximo o desprazer (entendido como aumento da excitação sexual, ou ainda, do que denominamos "comichão") e proporcionar de modo mais imediato o prazer (isto é, o rebaixamento daquela 
excitação) nas zonas erógenas. E uma vez que a sexualidade não está sob o domínio de um órgão específico do corpo, ela deve ser satisfeita no local mesmo de onde surgiu. Além disso, elas prescindem também da criação de mecanismos psíquicos que norteiem a ação voluntária no mundo exterior. Consequentemente, para ela, pensar e agir são indistintos para elas. Ela pode muito bem se satisfazer no mundo da fantasia.

E o que a consciência tem a ver com tudo isso? Segundo Freud, é ela (e a instância contigua a ela, qual seja: o pré-consciente) que possui a chave para a motilidade voluntária. É a consciência que passa a organizar o modo como a satisfação das pulsões de auto-conservação se dá no mundo, ao passo que as sexuais não necessitam ser organizadas por ela para encontrar satisfação. A organização que a consciência cria para a satisfação dos impulsos de conservação de si pressupõe uma regra fundamental, a saber: o princípio de realidade. Este será entendido como a capacidade do psiquismo tolerar, por um tempo um maior, o desprazer, a fim de poder encontrar o modo e o objeto corretos para a sua satisfação. Se as pulsões de auto-conservação seguissem o modelo de satisfação auto-erótica (que não tolera a espera e o desprazer), o corpo teria de consumir a si mesmo e destruir a si mesmo. O julgamento de realidade é, portanto, de importância capital para que estas pulsões encontrem sua satisfação e para que o corpo não pereça. Sem ele, a manutenção da vida não seria possível. A realidade é, consequentemente, uma construção que visa medir se um ato produziu efetivamente uma modificação no mundo exterior.

Tendo em vista o que dissemos até aqui, podemos afirmar que o corpo, fonte das excitações pulsionais, permite a criação de dois modos distintos de funcionamento psíquico: um ligado à consciência e outro ao inconsciente. Ou ainda, a dualidade dos impulsos que brotam do corpo possibilitam a construção de dois mundos distintos: aquele que denominamos efetivo (com modificação do exterior mediante um ato motor) e o que tomamos por fantasioso (que por não produzir tal modificação, é julgado como pertencente ao mundo interno - o dos pensamento).

Mas a psicanálise não cairia no vazio, uma vez que toma como causa do adoecimento uma mera ficção, destituída de valor objetivo? Todas as criações psíquicas impelidas pelo inconsciente (da qual o sonho é exemplo) estão impossibilitadas de diferenciar realidade efetiva e construção fictícia. Algumas em maior grau (como nos sonhos ou nas psicoses alucinatórias), outras em menor (como nas fantasias diurnas dos histéricos). Contudo, nem por isso estão dissociadas de realidade (Realität): uma vez que são capazes de produzir adoecimento, são tão reais quanto os eventos do mundo exterior. Não menos verdadeira que os eventos atribuídos pela consciência aos acontecimentos externos, os pensamentos inconscientes são dotados de uma realidade especial, denominada realidade psíquica (psychische Realität).

Duas diferentes formas de se conceber o mundo são, assim, possíveis em psicanálise: uma segundo o princípio de prazer, ligada ao universo inconsciente, outra segundo o de realidade, associado à consciência. Ambas têm o corpo como fonte de estímulos que pressionam o psiquismo a escoar o acúmulo de excitação e eliminar o desprazer. Nos dois casos, temos o surgimento de excitações no corpo que acabam por se representar no psiquismo. O processo de construção da representação parte de um fundo corpóreo até chegar, como no microscópio ótico, à sua forma virtual. Como se percorrêssemos o caminho que metaforicamente vai das raízes às folhas, também no processo representativo há uma base da representação que se fundamenta ou penetra no interior do corpo. Desse fundo, algo cresce ou vem à luz: todas as representações psíquicas.

Mas o caminho inverso, que vai do efeito à causa, ou ainda, da representação ao fundo, parece nos levar às profundezas do psiquismo. O conhecimento da gênese e das regras que regulam as representações não pode ser dissociado da base somática. A intelecção do que se apresenta à nossa vista não pode estar separada de uma visão das profundezas, a saber: de como partindo da representação chegamos 
ao conhecimento da fonte da pulsão. A questão que colocamos então é: até onde conhecemos verdadeiramente as pulsões?

\section{A pulsão como problema epistemológico}

A exposição da teoria freudiana conduzida até o momento pode nos fazer pensar que sendo a pulsão sexual não submetida às regras do pensamento consciente, apenas elas estariam fora do campo do conhecimento claro e límpido da consciência. Pode parecer, em um primeiro momento, que a pulsão de auto-conservação, que tem de se adequar às regras da consciência para alcançar o seu fim, seria a única sobre a qual recairia um esclarecimento total de seus mecanismos, que poderiam ser seguidos e conhecidos desde a fonte até sua satisfação. Contudo, uma informação dada por Freud em O inconsciente (1915) parece acirrar os pontos paradoxais de seu pensamento. O psicanalista escreve:

Uma pulsão nunca pode se tornar objeto da consciência, mas somente a representação (Vorstellung) que a representa (repräsentiert). Mas também no inconsciente ela não pode ser representada (repräsentiert) de outra forma que não pela representação (Vorstellung). Se a pulsão não se atasse a uma representação (Vorstellung) ou não se manifestasse como um estado afetivo (Affektzustand), então nada poderíamos saber dela. (FREUD, 1915a, p. 275-6)

Nesse texto, Freud traça uma clara distinção entre o representante pulsional e a pulsão. Esta, enquanto estímulo endógeno, não passa de um dado bruto, que não se apresenta diretamente ao psiquismo - mesmo as pulsões de auto-conservação. Temos notícia dos impulsos unicamente quando eles foram de alguma maneira trabalhados para que pudessem se tornar psiquicamente apresentáveis. Em si mesmas, as pulsões são inapreensíveis.

Ora, voltamos a um problema colocado no início do texto: haveria, assim, um corte entre o somático e o anímico, de tal modo que ambos formem mundos separados e independentes entre si? Para responder a essa questão, basta termos em vista o que foi apresentado nos itens anteriores: o corpo é a fonte de impulsos sexuais e de auto-conservação que, ao se acumularem, ganham representação no psiquismo. O que age no corpo, age também no psiquismo, e vice-versa. Devemos somar a isso o fato de a pulsão ser, tal como afirma Freud, um "conceito fronteiriço entre o anímico e o somático" (FREUD, 1915b, p.214). Se se chega a um ponto paradoxal, isso possivelmente se deve à ambiguidade que reside nesse caráter fronteiriço: como na imagem da planta, temos também para as pulsões uma parte que sempre se esconde da vista, e outra que cresce em direção à claridade. Esta é a metade psíquica dos impulsos, isto é, que ganha representação, que pode ser expresso em palavras, conceitualizado. A outra metade, que se esconde no somático, tomada em si mesma, não passa de uma grande incógnita. Isso não quer dizer que haja separação ou independência das duas metades (mesmo no que diz respeito ao conhecimento das pulsões). E como entender esse ponto limite da teoria freudiana, em que a parte cognitiva tenta apreender a incognoscível?

Segundo Freud, em A interpretação dos sonhos (FREUD, 1900 [1899], p. 240-41), todo dado corporal que se apresenta psiquicamente é uma interpretação, nunca um puro dado bruto ${ }^{2}$. Este jamais é apreendido pelo psiquismo. Com a concepção de pulsão, abre-se na teoria freudiana um ponto irredutível ao fechamento conceitual e à completa cognição. O núcleo do inconsciente, de onde brotam as pulsões, jamais

\footnotetext{
2 A esse respeito, ver também NAMBA, 2012, p. 54. Nesse artigo, a autora escreve: “Pode-se dizer então que a representação é ela própria uma interpretação, pois reconstitui o caminho que se deu desde a periferia até o córtex cerebral como uma interpretação feita pelo sonhador ao ser impelido pelo desejo de dormir no momento em que sonha".
} 
pode ser abarcado totalmente pela consciência. Esta apreende as pulsões sempre de maneira indireta, trabalhada. Esse fato, ao contrário do que pode parecer, não depõe contra os poderes anímicos. Se, por um lado, nossa capacidade cognitiva não é absoluta - Freud não é um autor pré-crítico! - e não nos dá acesso direto ao somático, por outro, abre-se para o anímico o poder de construir a representação (ou ainda, de ser ativo diante de um dado que chega até ele vindo do corpo). É a essa qualidade ativa do psiquismo que Freud denomina interpretação. Mais especificamente, o interpretar permite à alma dar visibilidade ao que não é, por natureza, visível para a consciência ${ }^{3}$. E como fazer isso sem que o inconsciente e seu fundo incognoscível se esgotem no tornar-se consciente? A interpretação é uma capacidade plástica do psíquico, que consegue modelar e compor em uma unidade coisas contraditórias. Ela consegue, assim, expor animicamente a pulsão, sem que esta perca a sua irrepresentabilidade. E o mesmo acontece no processo analítico: a interpretação psicanalítica consegue expor os impulsos inconscientes sem que estes sejam corrompidos em sua verdade, realidade e natureza.

Para deixarmos essa ideia mais clara, podemos pensar na tradução de um texto escrito em uma língua estrangeira completamente diferente da nossa. Um bom tradutor consegue comunicar o texto original na nossa língua sem que aquele perca sua força expressiva. O que temos na tradução é um escrito versado em outro idioma, com novas regras gramaticais, e algumas vezes utilizando-se até mesmo de um alfabeto diferente. Contudo, quando bem feita, a tradução consegue manter na nova versão a ideia original do autor, expressando-a com toda a sua força.

Para concluirmos, podemos dizer que a tradução é exercida em um campo comum aos dois idiomas - no original ou na nova versão, não saímos da linguagem. O que a interpretação psicanalítica parece nos ensinar é que se falamos em apresentação psíquica de impulsos de auto-conservação e sexuais, em processos primários e secundários, em julgamento de realidade, em ato motor, em fantasia e em diferentes instâncias psíquicas, algo análogo a isso deve estar presente também no corpo. Talvez possamos conjecturar, ou ainda, interpretar que o que permanece é o homem, como um ser único, ainda que pensado de maneira dual. Mas isto não é uma deficiência do homem em sua unidade, e sim da consciência e de seu limitado poder cognitivo.

Endereço de correspondência: Departamento de Filosofia e Metodologia das Ciências, Universidade Federal de São Carlos - UFSCar, Rodovia Washington Luís, Km 235, s/n, Jardim Guanabara, CEP 13565-905, São Carlos - SP, Brasil. E-mail: anasoliva@ufscar.br

Conflito de interesses: Nenhum.

Todos os autores leram e aprovam a versão final submetida a revista Em curso.

\footnotetext{
${ }^{3}$ Referimo-nos aqui apenas à consciência, pois, sendo o inconsciente um querer cego, nada pode saber dos processos pulsionais que estão em sua origem.
} 


\section{Bibliografia}

Obras de Sigmund Freud:

FREUD, S. Gesammelte Werke. Frankfurt am Main: Fischer, 1999. (G.W. $)^{4}$

FREUD, S. Obras Completas. Buenos Aires: Amorrortu, 2006. (A.E.)

(1890) FREUD, S. Psychische Behandlung (Seelenbehandlung), G.W., V; A.E., I.

(1896) FREUD, S. Weitere Bemerkungen über die Abwehr-Neuropsychosen, G.W., I; A.E., III

(1900 [1899]) FREUD, S. Die Traumdeutung, G.W., II/III; A.E., IV/V.

(1905) FREUD, S. Drei Abhandlungen zur Sexualtheorie, G.W., V; A. E., VII.

(1915a) FREUD, S. Das Unbewu te, G.W., X; A.E., XIV.

(1915b) FREUD, S. Triebe und Triebschicksale, G.W., X; A.E., XIV.

(1933 [1932]) FREUD, S. Neue Folge der Vorlesungen zur Einführung in die Psychoanalyse, G.W., XV; A.E., XXII. (1950 [1897]) FREUD, S. Carta 69, A.E., I.

Obra de comentadores:

CACCIOLA, M. L. M. O. A vontade e a pulsão em Schopenhauer. In: As pulsões. São Paulo: Escuta/ Educ, 1995.

HANNS, L. A teoria pulsional na clínica de Freud. Rio de Janeiro: Imago, 1999.

LAPLANCHE, J. ; PONTALIS, J.-B. Fantasme originaire, fantasme des origines, origines du fantasme. Paris: Hachette Littératures, 1985. Vocabulaire de la psychanalyse. Paris: PUF, 1967.

MEMMI, G. Freud et la creation litteraire. Paris: L'Harmattan, 1996.

MONZANI, L. R. Freud: o movimento de um pensamento. Campinas: Editora da Unicamp, 1989.

NAMBA, J. Representação e tradução no texto de Freud sobre as afasias. Rapsódia: almanaque de filosofia e arte, n. 6, 2012.

PRADO Jr., B. Filosofia da psicanálise. São Paulo: Brasiliense, 1991.

RAVOUX, J.-P. De Schopenhauer a Freud. L'inconscient en question. Paris: Beuchesne, 2007.

SORIA, A. C. S. Do indivíduo à cultura: um estudo sobre Freud. Judiaí: Paco Editorial, 2012.

SOUZA, P. C. (org.) Sigmund Freud e o gabinete do Dr. Lacan. São Paulo: Brasiliense, 1990.

\footnotetext{
${ }^{4}$ Com exceção da Carta 69 (presente na edição da Amorrortu), todas as paginações das citações foram tomadas do original alemão.
} 